\title{
A qualitative exploration of barriers to medication adherence among patients with uncontrolled diabetes in Qatar: integrating perspectives of patients and health care providers
}

This article was published in the following Dove Press journal:

Patient Preference and Adherence

Myriam Jaam ${ }^{1}$

Muhammad Abdul Hadi ${ }^{2}$

Nadir Kheir ${ }^{3}$

Mohamed Izham Mohamed

Ibrahim'

Mohammad Issam Diab'

Samya Ahmad Al-Abdulla ${ }^{4}$

Ahmed Awaisu'

'College of Pharmacy, Qatar

University, Doha, Qatar; ${ }^{2}$ Leicester

School of Pharmacy, De Montfort

University, Leicester, UK; ${ }^{3}$ Faculty

of Medical and Health Sciences,

University of Auckland, Auckland,

New Zealand; ${ }^{4}$ Family Medicine,

Primary Healthcare Corporation,

Doha, Qatar
Correspondence: Ahmed Awaisu

College of Pharmacy, Qatar University,

PO Box 2713, Doha, Qatar

Tel +97444035596

Fax +974 4403555

Email aawaisu@qu.edu.qa
Purpose: To develop an in-depth understanding of the barriers to medication adherence among patients with uncontrolled diabetes attending primary health care (PHC) centers in Qatar by exploring and integrating patients' and health care providers' perspectives.

Participants and methods: A descriptive qualitative methodology was used in this study. A trained researcher conducted semi-structured face-to-face interviews at two PHC centers. Patients with uncontrolled diabetes (with varied sociodemographic characteristics) and their respective health care providers (physicians, pharmacists, nurses, dieticians, and others) were purposively selected from the two PHC centers. All interviews were audio recorded, transcribed verbatim, and analyzed using thematic content analysis.

Results: Thirty interviews (14 patients and 16 health care providers) were conducted. A number of barriers to medication adherence were identified and classified broadly under three main themes: 1) patient-related factors, which included patients' individual characteristics and patients' perception, attitude, and behavior; 2) patient-provider factors, which included communication and having multiple health care providers caring for the patient; and 3 ) societal and environmental factors, which included social pressure and traveling to visit friends and relatives.

Conclusion: Patients with uncontrolled diabetes face multiple barriers to medication adherence. Similar themes emerged from both patients and their care providers. This research highlights the need for concerted multidimensional efforts and series of interventions to overcome these barriers. One vital intervention is expanding the scope of pharmacists' role within the PHC centers through providing medication reconciliation, patient-tailored medication counseling, and medicines use review, which may improve treatment outcomes among patients with diabetes.

Keywords: medication adherence, Middle East, primary health care, qualitative research, uncontrolled diabetes

\section{Introduction}

Diabetes mellitus (DM) is now considered a pandemic noncommunicable disease worldwide. ${ }^{1}$ In 2017 , over 400 million people ( $8.8 \%$ of the world population) were diagnosed with diabetes worldwide. ${ }^{2}$ Diabetes can fairly be managed by following a healthy lifestyle and taking appropriate medications, allowing patients to live a normal healthy life. ${ }^{1,2}$ On the other hand, uncontrolled diabetes can lead to various micro- and macrovascular complications of the disease. ${ }^{1}$ One-third of all patients with diabetes develop retinopathy, and a lower limb or a part of the lower limb is amputated every 
30 seconds due to uncontrolled diabetes. ${ }^{2}$ Medication nonadherence is globally recognized as a major contributor to treatment failure. ${ }^{3-6}$ Nonadherence to antidiabetic medications is not only of health concern, but also contributes to increased health care resource utilization and increased health care costs. $^{7-10}$ The Middle East and North African region spends about $17 \%$ of its health care budget on managing diabetes and its complications, which is the highest among all other regions of the world. ${ }^{2}$

Medication nonadherence rate in diabetes ranges between $38 \%$ and $41 \%$ within the Gulf region (Saudi Arabia, Oman, United Arab Emirates, Kuwait, and Qatar). ${ }^{11}$ In Qatar, a recent study has reported a very high medication nonadherence rate $(73 \%)$ among patients with uncontrolled diabetes within primary health care (PHC) setting. ${ }^{12}$ This alarming high rate of nonadherence reaffirms the need for further investigations to determine the barriers to medication adherence in patients with diabetes.

A number of studies and reviews conducted internationally have identified numerous barriers to medication adherence in patients with diabetes. ${ }^{13-21}$ However, most of these studies reported reasons for medication nonadherence from the patients' perspective and only a few studies explored health care providers' perspective. 5,15,22,23 Furthermore, previous studies focused on patients with diabetes in general, and little or no attention was devoted to patients with uncontrolled diabetes, a group that is highly vulnerable to the complications of the disease and increased health care costs. ${ }^{13-21,24}$ Understanding the perspectives of both health care providers and patients is crucial in designing viable effective interventions and for the delivery of high-quality health care. Therefore, the primary objective of the present study was to explore the barriers to medication adherence among patients with uncontrolled diabetes within primary care by integrating the perspectives of the patients and their health care providers.

\section{Overview of management of diabetes in Qatar}

In Qatar, once a patient is diagnosed with diabetes, they are initiated on medications by their health care provider and are generally followed up by the PHC center nearest to their home. Within the PHC center, during a routine follow-up visit, a nurse would take the patient's vital signs and blood glucose levels, which are then recorded on the patient's electronic medical file. The patient is then seen by a specialist nurse who tries to identify and resolve issues the patient is facing in relation to their diet and medications, if any. The patient also spends about 15-20 minutes with the health educator, who sends the patient to the physician, along with notes taken during their interaction with the patient. The physician would assess the patient and the health educator's notes, and would provide a new prescription or a refill for their current medications. The patient would then go to the pharmacy to receive their medication, or to the phlebotomy laboratory if the physician requested a blood test, or to a dietician or other health care providers, if needed. Once stable, the patient can be prescribed medications with three refills, each with 2 months' supply. Within the clinic, the pharmacist performs detailed patient counseling only upon the physician's request or if the patient appears to be confused about their medications. However, this is minimally done due to the large number of patients received by the PHC centers.

\section{Participants and methods}

A descriptive qualitative methodology using semistructured, face-to-face interviews was used in this study. Frequently used in health services research, qualitative description is considered the method of choice when description of patients' or health care professionals' experiences with a specific phenomenon is required. ${ }^{25}$ The study received ethics approval from the Primary Health Care Corporation Clinical Affairs Department in Qatar (PHCC/ IEC/16/04/013).

Both patients and health care providers were recruited from two PHC centers (Airport Health Center and West Bay Health Center). There are 17 PHC centers in the country and these two centers were purposively selected as they include a noncommunicable diseases clinic and represent the central region of the country covering majority of patients with diabetes. None of the authors had any professional or personal relationship with the study participants (patients or health care providers).

\section{Patients' selection}

A purposive sample of adult patients (aged $\geq 18$ years) attending one of the two PHC centers for at least 1 year with a confirmed diagnosis of diabetes (for at least 1 year) that was uncontrolled ( $\mathrm{HbA} 1 \mathrm{c}$ value above $7 \%$ or a fasting blood glucose above $7.2 \mathrm{mmol} / \mathrm{L})^{26}$ was included. Patients' medical records were reviewed by a researcher $(\mathrm{MJ})$ to identify patients meeting the inclusion criteria. Patients who were not able to speak Arabic and/or English were excluded from the study. Patients were selected from diverse ethnic and cultural backgrounds and from both genders to broaden the perspectives on the topic. 


\section{Health care providers' selection}

Health care providers (physicians, pharmacists, nurses, health educators, social workers, and dietitians) were also purposively selected and were included in the study if they were practicing in one of the two participating PHC centers for at least 1 year and were directly involved in providing care to patients with diabetes.

\section{Data collection}

The semi-structured interviews were conducted in English or Arabic based on the participants' preferences by a trained qualitative researcher (MJ) who was fluent in both Arabic and English. An interview guide containing open-ended probing questions was developed based on a conceptual framework model developed for this study. ${ }^{27}$ Briefly, the interview guide covered six different categories of barriers (medication-, health care provider-, patient-, diabetes-, health care system-, and societal-related barriers). The interview guides were independently reviewed and validated by two experienced qualitative researchers (NK, MAH) to ensure comprehensiveness of the interviews. The interview guides were then piloted on two participants to assess validity, feasibility, and burden. Since there were no changes to the interview structure, the piloted interviews were included in the analysis. The interview guides are available in Figures S1 and S2 in the Supplementary materials. The interviews were conducted face-to-face in quiet areas within the centers and were audiotaped for transcribing purposes. The process of recruitment and interview continued until data saturation was achieved. ${ }^{28}$ An approximate number of 20 interviews were deemed appropriate based on a previous study conducted in Kuwait. ${ }^{29}$ Each interview lasted between 30 and 45 minutes.

\section{Data analysis}

Data were analyzed manually using thematic analysis technique. The same researcher who conducted the interviews (MJ) transcribed the transcripts verbatim. Notes of potential codes were taken during transcribing and then compared and integrated with the final codes. Transcripts were then formally coded and recoded through inductive coding for common phrases that discussed the same idea or meaning. ${ }^{30}$ Irrelevant codes were discarded and similar codes were collated and placed under respective themes. Themes were then checked against each other and finalized. Two researchers (NK, MJ) independently conducted this process to ensure consistency and reliability of coding and themes generated and trustworthiness of the data analysis. Review of the identified themes and consensus and opinions of all research team members were used to finalize the themes.
To ensure trustworthiness of this research, data obtained from patient interviews and health care provider interviews were triangulated to reduce potential biases. ${ }^{31}$ In addition, the researchers took daily reflection notes during and after the interviews. These notes were taken into consideration during data analysis. Quotes representing each theme/subtheme were chosen based on agreement from all research members. Finally, peer debriefing and analytic triangulation were conducted throughout the research with skilled qualitative researchers. ${ }^{31}$

\section{Informed consent}

We confirm all participants' identifiers have been removed or disguised, so participants described are not identifiable and cannot be identified through the details of the story. Written informed consents were obtained from both patients and health care providers. Patients' anonymity and confidentiality were ensured throughout the research.

\section{Results}

Fourteen patients with uncontrolled diabetes consented to participate in the study (Table 1). The mean duration of the interviews was $33.9 \pm 16.2$ minutes. The mean $( \pm \mathrm{SD})$ age of the interviewees and duration of their diabetes were 58.3 $( \pm 8.1)$ and $11.4( \pm 6.2)$ years, respectively. The mean $( \pm \mathrm{SD})$ of $\mathrm{HbAlc}$ was $9.9 \%( \pm 1.4)$. All interviewed patients were taking metformin as part of their diabetes treatment regimen, while five were taking insulin concomitantly. Six patients had neuropathy, three had nephropathy, and two had retinopathy.

On the other hand, 16 health care providers with diverse characteristics (Table 2) were interviewed. On average, each interview lasted for $46.5 \pm 15.3$ minutes. The average duration of practice experience of the health care providers was $7.5 \pm 5.9$ years. Since the number of health care providers is small (relative to those practicing in PHC center as compared to patients attending the PHC centers), their characteristics are summarized collectively (not individually) in order to maintain anonymity (Table 2).

\section{Barriers to medication adherence}

Three main themes emerged from the health care providers' and the patients' interviews. Figure 1 represents all the identified themes and subthemes that emerged from the interviews.

\section{Theme: patient-related factors}

Two subthemes including patients' individual characteristics and patients' perceptions, attitude, and behavior emerged in the patient-related factors theme. Each of these subthemes is described in detail below without any specific hierarchy/order. 
Table I Characteristics of patients with uncontrolled DM who participated in qualitative interviews ( $\mathrm{N}=14)$

\begin{tabular}{|c|c|c|c|c|c|c|}
\hline Pt no & Nationality & Gender & Religion & Education level & $\begin{array}{l}\text { Number } \\
\text { of diabetes } \\
\text { medications }\end{array}$ & $\begin{array}{l}\text { Diabetes } \\
\text { complications }\end{array}$ \\
\hline Pt I & Indian & Male & Hinduism & University & I & I \\
\hline Pt 2 & Sudan & Male & Islam & University & 2 & 2 \\
\hline Pt 3 & Indian & Female & Hinduism & High school & 3 & 0 \\
\hline Pt 4 & Sri Lankan & Male & Buddhism & Primary school & 2 & I \\
\hline Pt 5 & Yemeni & Male & Islam & University & 2 & 0 \\
\hline Pt 6 & Sudan & Male & Islam & Primary school & 5 & 4 \\
\hline Pt 7 & Egyptian & Female & Islam & Secondary school & 2 & 2 \\
\hline Pt 8 & Iranian & Male & Islam & Primary school & 2 & 0 \\
\hline Pt 9 & Qatari & Male & Islam & Illiterate & 3 & 2 \\
\hline Pt 10 & Sri Lankan & Female & Buddhism & Diploma & 2 & 2 \\
\hline Pt II & Indian & Male & Hinduism & University & 2 & 0 \\
\hline $\mathrm{Pt} 12$ & Egyptian & Female & Islam & High school & 3 & 2 \\
\hline $\mathrm{Pt} 13$ & Pakistani & Male & Islam & High school & 3 & 0 \\
\hline Pt 14 & Palestinian & Male & Islam & University & 4 & 0 \\
\hline
\end{tabular}

Abbreviation: Pt no, patient number; DM, diabetes mellitus.

\section{Patients' individual characteristics}

A number of individual patients' characteristics including age, socioeconomic status, education level, working conditions, and religious beliefs were recognized as important barriers to medication adherence by both patients and health care providers. Some health care providers perceived that older individuals tend to have lower adherence than younger adults. However, some health care providers felt otherwise.

[...] As you get older, you would forget [...] because it's also with older age, you would be on other medications. [HCPI 4]

Table 2 Characteristics of health care providers caring for patients with uncontrolled diabetes who participated in qualitative interviews $(\mathrm{N}=16)$

\begin{tabular}{l|l}
\hline Variable & $\mathbf{n}$ \\
\hline Gender & 10 \\
Female & 6 \\
Male & 5 \\
Nationality & 2 \\
Egyptian & 1 \\
British & 1 \\
Filipino & 3 \\
Indian & 2 \\
Jordanian & 2 \\
Qatari & \\
Sudanese & 6 \\
Profession & 5 \\
Pharmacist & 2 \\
Physician & 1 \\
Nurse & 1 \\
Health educator & 1 \\
Social worker & Dietician
\end{tabular}

On the contrary, I find that older people are more careful and they come to their appointments [...] [HCPI 7]

Health care providers perceived that educated patients are more likely to be adherent than those who are less or not educated.

Of course if the patient is highly educated he would be able to receive the information and stick to the information that he received and everything will go smoothly. [HCPI 5]

Although medicines are available at very subsidized cost to Qatari and non-Qatari (only 20\% of the total cost), patients

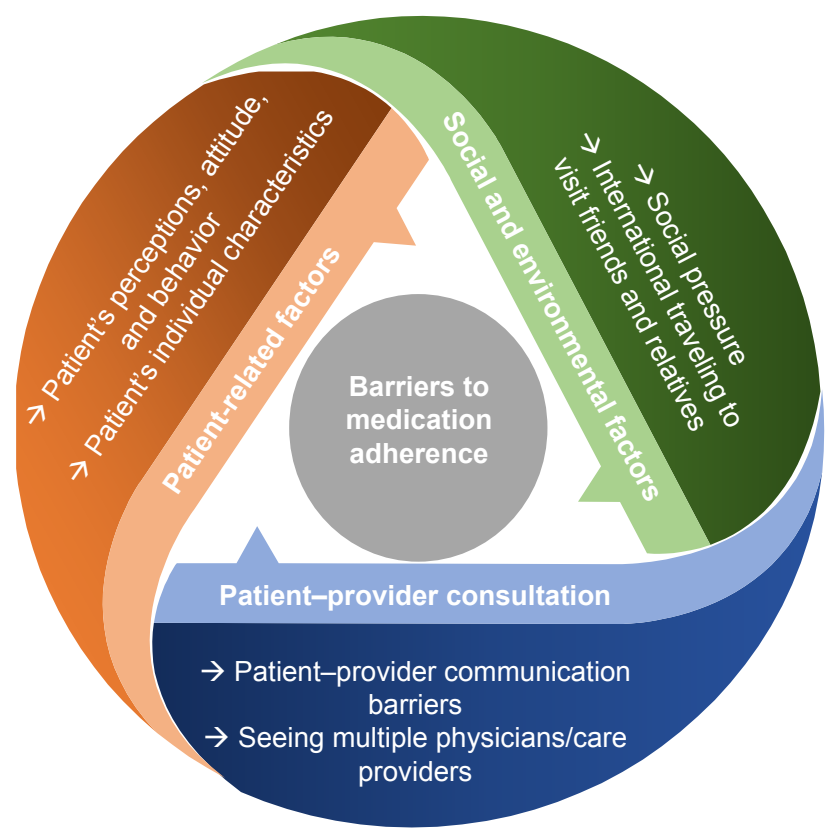

Figure I Barriers to medication adherence. 
from deprived socioeconomic backgrounds found it difficult to pay for their medicines, leading to nonadherence.

[...] you can see the medication is not expensive and is available, but despite this there are some who can't afford [...] [HCPI 7]

Medication is expensive because I am jobless [... [PI 13]

Religious beliefs and rituals also had an impact on patients' adherence. For example, patients who fast tend to reduce the dose or stop taking their medicines because they believe that they do not need to take them as they are not eating much.

There is one-month fasting but not complete; we can use vegetable, not non-vegetable. Light food and I do not use insulin. Only vegetable, so I do not think this will increase my sugar. [PI 1]

I change the dose in Ramadan by myself [...] It's two times [...] morning and evening same [...] [PI 13]

At many instances, the patients' working conditions appeared to have negative impact on medication adherence. During busy times, patients often forget to take their medicines.

I observed those patients who are busy and working and have stress also sometimes they are not compliant with the medicine. [HCPI 8]

\section{Patients' perceptions, attitude, and behavior}

Inadequate knowledge coupled with negative perceptions and attitudes about diabetes and its management were other factors affecting medication adherence. Some health care professionals indicated that sometimes patients find it difficult to believe that they have diabetes, and therefore, they do not take the medications as instructed.

There are patients who deny they are sick and they are not convinced they need all these medications, especially in the elderly [...] I see this. [HCPI 3]

A number of patients expressed negative attitudes toward the use of insulin. Patients not only expressed fear with the use of needles, but also have the perception that initiation of insulin meant that they had failed at managing their disease.

Once you start insulin, means you have to continue $[\ldots]$ you cannot stop it, your body will get used to it, and that's it, no escape. [PI 3]
Yes that is the biggest barrier: starting patients on insulin. I had this problem with two or three patients. First it's the needle phobia, they do not like this every day needle; second it's the understanding, like this [insulin] means there is no hope, this is bad thing gone very bad; so I think it affects their whole lifestyle. [HCPI 13]

Although health care providers try their best to convince patients about the importance of insulin in managing their diabetes, patients still exhibit resistance to taking insulin.

People have a fear from insulin, and at many times they really refuse to take it, so you see a doctor going for Quadramed oral [four different diabetes medications] which is really weird because it's not recommended by any guideline. [HCPI 12]

On the other hand, patients who were receiving insulin tend to adjust the dose of insulin themselves based on their diet on a particular day, without consulting their health care professionals. In many instances, such changes would result in patients experiencing side effects such as hypoglycemia.

When my blood sugar is high, I would take higher dose, I just do it myself, I estimate and I just take it when my sugar is high. Like yesterday, I didn't eat or anything, and I do not know why my blood sugar was high. For the first time I found it 300 , so for 300 the only thing that works is insulin dose. When I took it, unfortunately, I got hypoglycemia at night [...] [PI 7]

Patients' perceptions about the effectiveness of medicines also played an important role in medication adherence. Few patients held negative perceptions about the effectiveness of treatment and considered that the treatment is only targeted to make profits for pharmaceutical companies, but not to improve patient outcomes.

I have used all the tablets, but, in my opinion, these tablets are useless. They should stop them! It doesn't have any effectiveness. [PI 2]

They [Pharmaceutical Industry] do not want to help people, because keeping them as they are means yearly profit of billions and billions of dollars. If they cure you, they lose all this money. [PI 14]

\section{Theme: patient-provider consultation}

Two subthemes, patient-provider communication and seeing multiple physicians/health care providers emerged under patient-provider consultation theme. 


\section{Patient-provider communication barriers}

Both patients and health care professionals understood the importance of effective communication between the patient and health care provider in ensuring better medication adherence and treatment outcomes, but highlighted a couple of barriers to effective communication. A couple of health care providers highlighted inability of some of the patients to speak and understand in Arabic or English, which made it difficult for them to effectively counsel patients on lifestyle and disease management.

There are those who have language issues, so they do not understand, they receive the medicine but they do not know how to take it. [HCPI 11]

Limited time for consultation with primary care physicians also acted as a barrier to have a detailed discussion about patients' symptoms, disease progression, and treatment options and their effectiveness. Pharmacists also described their inability to counsel patients effectively about the use of medicines because of mounting workload pressure.

There is not really enough time, actually there is never enough time, but you also can't do it all in one visit. [HCPI 12]

I do not know if he [the patient] is taking his medications because I do not ask [... I I just dispense here, and that's it. There is no time to even deal with him [the patient] much, given the pressure here in this center. [HCPI 4]

\section{Seeing multiple physicians/care provider}

Continuity of care from a health care provider was considered necessary by both patients and health care providers in improving adherence. Some patients indicated that seeing more than one care provider for the same issue (ie, diabetes) could create confusion and complications in the care management plan. Patients were either given appointments with different primary care physicians at the same center based on physicians' availability or the patients sometimes opted to access different health care institution.

There was a patient $[\ldots]$ one physician told him there is no need to take this medication while another tells him no you should take it. [HCPI 3]

I saw so many doctors here. I once told my friend [...] I told him in [name of the clinic], it's like the United Nations [...] One day it's Indian, one day it's Egyptian, one day it's Sudanese, one day it's Jordanian, and each has his own way of doing things. [PI 2]
I'm following up with another physician outside in [name of the clinic] [...] because I have private insurance as well. [PI 2]

\section{Theme: social and environmental factors}

Social and environmental factors affecting medication adherence included two subthemes: social pressure and traveling to visit friends and relatives (VFR).

\section{Social pressure}

Both patients and health care providers frequently highlighted social pressure and stigma associated with diabetes as a barrier to medication adherence. Patients often found it difficult to disclose their disease condition even to close family members and friends. This made patients reluctant to take medicines in front of family and friends, which led to missing doses and medication nonadherence.

I had one patient with type 1 diabetes, and she got married and pregnant, and she did not tell her husband she is diabetic. [HCPI 10]

Patients also indicated that it is difficult to take injections in the presence of other people as it gives a negative impression about them being drug addicts as, culturally, injections are associated with addiction.

Honestly, I intentionally sometimes not take [injections] it in front of people [...] I remember I was once taking insulin and someone got up $[\ldots]$ and from far he screamed $[\ldots]$

hey heroine! [PI 2]

On the other hand, patients with diabetes tend to influence their peers by sharing information about the disease and the medications and providing advice on the best treatment based on their experience.

Honestly I asked him [the physician] to prescribe it [sitaglip-

tin] for me [...] because my siblings in [name of country] are taking it and they are doing well. [PI 12]

\section{International travel to VFR}

There was a consensus among all the interviewed participants that traveling to VFR is a big barrier to medication adherence. This was especially true for immigrant workers who often go back to their home countries during vacations. Patients believed that their sugar levels get better in their home countries, and therefore, they either reduce the dose or stop taking the medications. 
When I go to [name of country], I think my sugar can be controlled without insulin, because I move. [PI 7]

He [patient] has an idea that when traveling to his home country, he will get better and his health will improve. [HCPI 14]

There was a tendency among some patients to use herbal and other natural remedies available locally in their own countries, such as mixtures of garlic, cinnamon, ginger, roselle, and other herbal products. Subsequently, patients would stop taking their medicines, as they believe that taking herbal/natural remedies could help them control sugar levels without having side effects.

I take [name of country] medicine. When I am in [name of the country], I take it because it is more effective and has fewer side effects. [PI 4]

Our grandparents, they teach us these are good and they come from nature, so they are good. [PI 10]

\section{Discussion}

To our knowledge, this is the first study conducted in Qatar and the Middle East and North African region to investigate barriers to medication adherence among patients with uncontrolled diabetes from both patients' and health care providers' perspectives using qualitative methodology. ${ }^{11}$ Diabetes and its complications are highly burdensome. ${ }^{32,33}$ To improve medication-taking behavior, it is important to understand the reasons of nonadherence in the first place. The main findings of this research indicate that barriers to medication adherence are multifactorial and involve multiple parties including the patient, the health care providers, and the society. Many of the barriers identified in this research, such as patient-provider communication, negative motivators to adherence, information, and knowledge, as well as financial issues, were also highlighted by Brundisini et al. ${ }^{23}$

Studies investigating medication adherence have identified many patient-related aspects and have linked some sociodemographic characteristics to nonadherence. ${ }^{8,17,19,29,34-39}$ Working conditions such as traveling and prolonged working hours, in particular, were found to be problematic. This finding emphasizes the importance of enquiring about the working conditions of patients with diabetes and identifying how they can contribute to medication nonadherence rather than just associating employment status alone to medication adherence.

Family support plays an important role in diabetes management and control. ${ }^{40}$ Nonetheless, an interesting notion in patients with diabetes, particularly those on insulin, was that they were willing to conceal their disease from their loved ones due to the fear of being stigmatized. Hiding such information could mean that the patient may not be taking the prescribed medications in front of the family members. This further emphasizes the importance of family support and the need for family involvement in the management and care of the patient with long-term conditions such as diabetes. The fear of being rejected or stigmatized stems from the society's misconceptions about and stereotyping of diabetes. Patients indicated that they do not like to take medications in public because they are worried about being discriminated, a behavior that is common among patients taking insulin. ${ }^{29,41}$ Brod et $\mathrm{al}^{42}$ and Snoek and Skinner ${ }^{43}$ both indicated that social stigma and the misconceptions about insulin can highly affect patients' acceptance of the medication. This reemphasizes the need for educating not only the patients but also the society about insulin.

Lack of patient education and counseling in relation to diabetes management and insulin dose adjustments can be a major contributor to the fact that patients are changing their medications according to what they deem appropriate. ${ }^{13,24,29,44,45}$ This, in many instances, results in the patient experiencing adverse events such as hypoglycemia. Changing physicians and the limited patient-provider interaction time can also contribute to the lack of disclosing information as time is often inadequate to interact with the patients, provide them with information, and listen to their illness story. ${ }^{8}$ This, in addition to language barriers, needs to be addressed by the health care institutions to improve patient outcomes. On the other hand, patients do not commonly inform their health care providers about the changes that they make to their medications, which can highly influence treatment outcomes. One reason for concealing information is the patient-provider relationship and trust. ${ }^{8,46}$

Lack of education was also reflected on the attitude of the patients toward insulin. Patients often refused to take it and avoided using it. Such an attitude prompts the review of the education provided to patients with diabetes, especially that the majority of patients may end up using insulin at some point in their lives. Perhaps, health care providers should prepare the patient from the initial diagnosis for the use of insulin, its benefits, and its risks prior to suddenly changing the patient to an injection. The necessityconcerns framework describes the two dimensions involved in medication adherence: the belief in the necessity of the medication (ie, benefit on diabetes, reduction in mortality 
and morbidity, etc) and the concerns regarding the treatment (ie, needle phobia, societal pressure, side effects, etc). ${ }^{47}$ When the necessity belief exceeds the concerns, the patient is most likely to adhere to their treatment. ${ }^{47}$ Therefore, the findings within this research in regard to insulin necessitate further research to determine the core reasons behind the negative attitude and to understand how to formulate a structured educational approach, which would increase the patients' necessity belief.

There is no single best solution or strategy to overcome all the barriers to medication adherence at once due to their multidimensional nature. Although numerous strategies and interventions aiming at improving medication adherence have been published, the best interventions are yet to be determined. ${ }^{48,49}$ Pharmacists play an important role in addressing medication adherence. ${ }^{49-52}$ Patients are not typically referred to the pharmacist for medication reconciliation despite the clear need for it. Therefore, there is a need to develop local guidelines and criteria on patient referral for medication reconciliation. In addition, the role of pharmacist should expand to allow them to perform medication reconciliation without the need for physician's referral.

\section{Limitations}

There are some limitations to this study, which need to be acknowledged. Selection bias might have occurred as it was possible that those who turned up to refill their medications and follow-up appointments and agreed to participate in the current study were those who are more likely to be adherent to their medications. Patients who did not attend to their appointments and those who could not speak either Arabic or English might have other important barriers and experiences that were not captured in this study. Since this was an interview-based research, social desirability and recall bias can undermine the quality of the data. However, this methodology is the best at obtaining reasons for nonadherence and influencing factors from the patients' perspectives. To minimize researcher bias, all interviews were conducted by the same researcher who had received formal training in undertaking qualitative interviews.

\section{Conclusion}

This study contributed to the existing body of knowledge through an in-depth understanding of the barriers to medication adherence in patients with uncontrolled diabetes in Qatar. Many of the barriers identified were directly related to patient information and knowledge about diabetes and its management. These would require concerted efforts and series of interventions which should be initiated in a step-wise approach. Future work should focus on creating population-specific interventions, taking into consideration the barriers identified within this study. Without overcoming barriers to medication adherence, it is highly unlikely to improve patient outcomes among patients with uncontrolled diabetes.

\section{Acknowledgments}

The authors would like to thank Qatar University for providing grant and the Primary Health care Corporation for providing the resources needed to conduct this project including the ethics approval. The authors thank all the pharmacists who were very supportive in the conduct of the study in the health centers. Finally, thanks to all the participants who contributed to enriching our knowledge about their experience.

This work was supported by Qatar University Student Grant (QUST-CPH-SPR 15/16-19). The funding source was not involved in the study design, data collection, analysis and interpretation of data, the writing of the report, and the decision to submit the manuscript for publication.

\section{Disclosure}

The authors report no conflicts of interest in this work.

\section{References}

1. World Health Organization. Diabetes fact sheet; 2017. Available from: http://www.who.int/mediacentre/factsheets/fs312/en/. Accessed May 11, 2018.

2. International Diabetes Federation. IDF Diabetes Atlas. 8th ed. Brussels: International Diabetes Federation; 2017.

3. Wabe NT, Angamo MT, Hussein S. Medication adherence in diabetes mellitus and self management practices among type-2 diabetics in Ethiopia. N Am J Med Sci. 2011;3(9):418-423.

4. García-Pérez LE, Álvarez M, Dilla T, Gil-Guillén V, Orozco-Beltrán D. Adherence to therapies in patients with type 2 diabetes. Diabetes Ther. 2013;4(2):175-194.

5. Cramer JA. A systematic review of adherence with medications for diabetes. Diabetes Care. 2004;27(5):1218-1224.

6. Polonsky WH, Fisher L, Guzman S, Villa-Caballero L, Edelman SV. Psychological insulin resistance in patients with type 2 diabetes: the scope of the problem. Diabetes Care. 2005;28(10):2543-2545.

7. Iuga AO, Mcguire MJ. Adherence and health care costs. Risk Manag Healthc Policy. 2014;7:35-44.

8. Jin J, Sklar GE, Min Sen Oh V, Chuen Li S. Factors affecting therapeutic compliance: a review from the patient's perspective. Ther Clin Risk Manag. 2008;4(1):269-286.

9. Cani CG, Lopes LS, Queiroz M, Nery M. Improvement in medication adherence and self-management of diabetes with a clinical pharmacy program: a randomized controlled trial in patients with type 2 diabetes undergoing insulin therapy at a teaching hospital. Clinics. 2015;70(2): 102-106.

10. Kirkman MS, Rowan-Martin MT, Levin R, et al. Determinants of adherence to diabetes medications: findings from a large pharmacy claims database. Diabetes Care. 2015;38(4):dc142098-dc142609.

11. Jaam M, Ibrahim MIM, Kheir N, Awaisu A. Factors associated with medication adherence among patients with diabetes in the Middle East and North Africa region: a systematic mixed studies review. Diabetes Res Clin Pract. 2017;129:1-15. 
12. Jaam M, Mohamed Ibrahim MI, Kheir N, Hadi MA, Diab MI, Awaisu A. Assessing prevalence of and barriers to medication adherence in patients with uncontrolled diabetes attending primary healthcare clinics in Qatar. Prim Care Diabetes. 2018;12(2):116-125.

13. Alrowais NA, Alhaider AA, Alhassan MI, Abou-Auda HS, Jarallah JS. A look at the diabetic patient compliance in Riyadh district. Saudi Pharm J. 1993;1(2):50-55.

14. Khattab MS, Aboifotouh MA, Khan MY, Humaidi MA, Al-Kaldi YM. Compliance and control of diabetes in a family practice setting, Saudi Arabia. East Mediterr Health J. 1999;5(4):755-765.

15. Krass I, Schieback P, Dhippayom T. Adherence to diabetes medication: a systematic review. Diabet Med. 2015;32(6):725-737.

16. Polinski JM, Smith BF, Curtis BH, et al. Barriers to insulin progression among patients with type 2 diabetes: a systematic review. Diabetes Educ. 2013;39(1):53-65.

17. Nam S, Chesla C, Stotts NA, Kroon L, Janson SL. Barriers to diabetes management: patient and provider factors. Diabetes Res Clin Pract. 2011;93(1):1-9.

18. Peeters B, van Tongelen I, Boussery K, Mehuys E, Remon JP, Willems S. Factors associated with medication adherence to oral hypoglycaemic agents in different ethnic groups suffering from type 2 diabetes: a systematic literature review and suggestions for further research. Diabet Med. 2011;28(3):262-275.

19. Sohal T, Sohal P, King-Shier KM, Khan NA. Barriers and facilitators for type-2 diabetes management in South Asians: a systematic review. PLoS One. 2015;10(9):e0136202.

20. Mcsharry J, Mcgowan L, Farmer AJ, French DP. Perceptions and experiences of taking oral medications for the treatment of type 2 diabetes mellitus: a systematic review and meta-synthesis of qualitative studies. Diabet Med. 2016;33(10):1330-1338.

21. Huang YM, Shiyanbola OO, Chan HY. A path model linking health literacy, medication self-efficacy, medication adherence, and glycemic control. Patient Educ Couns. Epub 18 June 2018.

22. Asche C, Lafleur J, Conner C. A review of diabetes treatment adherence and the association with clinical and economic outcomes. Clin Ther. 2011;33(1):74-109.

23. Brundisini F, Vanstone M, Hulan D, Dejean D, Giacomini M. Type 2 diabetes patients' and providers' differing perspectives on medication nonadherence: a qualitative meta-synthesis. BMC Health Serv Res. 2015 $15: 516$.

24. Berenguera A, Molló-Inesta À, Mata-Cases M, et al. Understanding the physical, social, and emotional experiences of people with uncontrolled Type 2 diabetes: a qualitative study. Patient Prefer Adherence. 2016;10: 2323-2332.

25. Sandelowski M. What's in a name? Qualitative description revisited. Res Nurs Health. 2010;33(1):77-84.

26. American Diabetes Association. Standards of medical care in diabetes 2014. Diabetes Care. 2014;37 (Suppl 1):S14-S80.

27. Jaam M, Awaisu A, Mohamed Ibrahim MI, Kheir N. A holistic conceptual framework model to describe medication adherence in and guide interventions in diabetes mellitus. Res Social Adm Pharm. 2018; 14(4):391-397.

28. Corbin J, Strauss A. Basics of Qualitative Research: Techniques and Procedures for Developing Grounded Theory. Thousand Oaks: SAGE Inc; 2008.

29. Jeragh-Alhaddad FB, Waheedi M, Barber ND, Brock TP. Barriers to medication taking among Kuwaiti patients with type 2 diabetes: a qualitative study. Patient Prefer Adherence. 2015;9:1491-1503.

30. Braun V, Clarke V. Using thematic analysis in psychology. Qual Res Psychol. 2006;3(2):77-101.

31. Hadi MA, José Closs S. Ensuring rigour and trustworthiness of qualitative research in clinical pharmacy. Int J Clin Pharm. 2016;38(3): 641-646.

32. International Diabetes Federation. IDF Diabetes Atlas. 7th ed. Brussels: International Diabetes Federation; 2015.
33. Aguiree F, Brown A, Cho N, et al. International Diabetes Federation Diabetes Atlas (Update); 2014. Available from: https://www.idf.org/ sites/default/files/Atlas-poster-2014_EN.pdf. Accessed October 29, 2015.

34. Delamater AM. Improving Patient Adherence. Clin Diabetes. 2006; 24(2):71-77.

35. Gellad WF, Grenard J, McGlynn EA. A Review of Barriers to Medication Adherence: A Framework for Driving Policy Options. Pittsburgh: RAND Corporation; 2009.

36. Gellad WF, Grenard JL, Marcum ZA. A systematic review of barriers to medication adherence in the elderly: looking beyond cost and regimen complexity. Am J Geriatr Pharmacother. 2011;9(1):11-23.

37. Grant RW, Devita NG, Singer DE, Meigs JB. Improving adherence and reducing medication discrepancies in patients with diabetes. Ann Pharmacother. 2003;37(7-8):962-969.

38. Odegard PS, Capoccia K. Medication taking and diabetes: a systematic review of the literature. Diabetes Educ. 2007;33(6):1014 1029. discussion 1030-1031.

39. Odegard PS, Gray SL. Barriers to medication adherence in poorly controlled diabetes mellitus. Diabetes Educ. 2008;34(4):692-697.

40. Mayberry LS, Osborn CY. Family support, medication adherence, and glycemic control among adults with type 2 diabetes. Diabetes Care. 2012;35(6):1239-1245.

41. Abu Hassan H, Tohid H, Mohd Amin R, Long Bidin MB, Muthupalaniappen L, Omar K. Factors influencing insulin acceptance among type 2 diabetes mellitus patients in a primary care clinic: a qualitative exploration. BMC Fam Pract. 2013;14:164.

42. Brod M, Alolga SL, Meneghini L. Barriers to initiating insulin in type 2 diabetes patients: development of a new patient education tool to address myths, misconceptions and clinical realities. Patient. 2014;7(4): $437-450$.

43. Snoek FJ, Skinner TC. Psychological aspects of diabetes management. Medicine. 2006;34(2):61-62.

44. Koprulu F, Bader RJK, Hassan N, Abduelkarem AR, Mahmood DA. Evaluation of adherence to diabetic treatment in northern region of United Arab Emirates. Trop J Pharm Res. 2014;13(6):989-995.

45. Khan AR, Al-Abdul Lateef ZN, Al Aithan MA, Bu-Khamseen MA, Al Ibrahim I, Khan SA. Factors contributing to non-compliance among diabetics attending primary health centers in the Al Hasa district of Saudi Arabia. J Family Community Med. 2012;19(1):26-32.

46. Martin LR, Williams SL, Haskard KB, Dimatteo MR. The challenge of patient adherence. Ther Clin Risk Manag. 2005;1(3):189-199.

47. Phillips LA, Diefenbach MA, Kronish IM, Negron RM, Horowitz CR. The necessity-concerns framework: a multidimensional theory benefits from multidimensional analysis. Ann Behav Med. 2014;48(1):7-16.

48. Vignon Zomahoun HT, de Bruin M, Guillaumie L, et al. Effectiveness and content analysis of interventions to enhance oral antidiabetic drug adherence in adults with type 2 diabetes: systematic review and metaanalysis. Value Health. 2015;18(4):530-540.

49. Vermeire E, Wens J, van Royen P, Biot Y, Hearnshaw H, Lindenmeyer A. Interventions for improving adherence to treatment recommendations in people with type 2 diabetes mellitus. Cochrane Database Syst Rev. 2005;2(2):CD003638.

50. Lindenmeyer A, Hearnshaw H, Vermeire E, van Royen P, Wens J, Biot Y. Interventions to improve adherence to medication in people with type 2 diabetes mellitus: a review of the literature on the role of pharmacists. J Clin Pharm Ther. 2006;31(5):409-419.

51. Antoine SL, Pieper D, Mathes T, Eikermann M. Improving the adherence of type 2 diabetes mellitus patients with pharmacy care: a systematic review of randomized controlled trials. BMC Endocr Disord. 2014; $14: 53$.

52. Jarab AS, Alqudah SG, Mukattash TL, Shattat G, Al-Qirim T. Randomized controlled trial of clinical pharmacy management of patients with type 2 diabetes in an outpatient diabetes clinic in Jordan. J Manag Care Pharm. 2012;18(7):516-526. 


\title{
Supplementary materials
}

\author{
Interviewer's guide (patients with diabetes in Qatar) \\ The following will be the focus of the discussion during the patient interviews. The thematic questions will be used as prompts and would \\ allow free expression of opinion from the participant.

\section{Start} \\ Welcome: Interviewer will welcome the participant. \\ General introduction: The interviewer will introduce him/herself. \\ Example \\ "Thank you for being here today. My name is ___, a research investigator at Qatar University. The main purpose of this interview is to \\ identify barriers to medication adherence in patients with diabetes like yourself and to explore the strategies that you think should be used \\ to improve medication-taking behavior and adherence. We are very interested to hear your opinions and learn from your experiences \\ regarding medication-taking and adherence.... The interview is a method of learning from experience both positive and negative. We are \\ not trying to achieve consensus; we are just gathering information to help us have an in-depth understanding of the context..." \\ Ground rules \\ 1. We want you to do the talking. Talk freely; there is no right or wrong answers. \\ 2. Try to reflect on your experiences with the diabetes medications. \\ 3. Whatever is mentioned within the room, will stay within the room and will not be linked back to you. \\ 4. We will tape record the discussion to capture everything you have to say, but we will not identify anyone by name in our \\ report, you will remain anonymous. This is to help us not to miss anything important that you say and so that we revisit the \\ information during transcribing if necessary. Tape records will be deleted once transcribed. \\ 5. You may refuse to answer any question or withdraw from the study at anytime. \\ 6. We would appreciate if you could please turn off your mobile phone to avoid distractions during the session. \\ 7. The duration of this interview is about $45-60$ minutes. \\ Participant's introduction \\ Ask participants to introduce themselves, their work, and how long they have been in Doha for. \\ Example: \\ 1. Can you tell me the story of your diabetes? When did it start? How are your levels? \\ Introductory questions \\ 1. What medications are you taking for diabetes? \\ 2. When did you start these medications? \\ 3. Have you had any difficulties in taking your medications as prescribed by your doctor?
}

Barriers to medication adherence

1. What do you understand about the role of medicines in the management of DM?

a. Prompt: Did your doctor explain how medicines should be taken.

b. Prompt: Do you think that you completely understand how meds should be taken.

2. What barriers do you encounter in taking your medications for diabetes?

3. What about these factors:

i. Patient - related factors:

a. Demographics (gender, age, education, marital status, ethnicities, financial status).

b. Psychological status (stress, fear, motivation).

c. Knowledge.

d. Perceptions/beliefs.

e. Comorbidities.

f. Other (fasting, traveling, weekend, forgetfulness).

ii. Medication - related factors: frequency, duration of therapy, polypharmacy, timing, side effects, complexity of treatment, etc.

1. Why do you think it is important to take medicines as prescribed by physicians.

2. What do you do when you experience any side effects.

3. Does the fear of side effects influence your decision for taking or not taking medications?

Figure SI (Continued) 
iii. Disease - related factors: disease duration, complexity, low HbA1c, complications

iv. Provider - related factors: support, inclusion in decision making, relationship, language, assumptions

v. Healthcare system-related factors: cost, lack of guidelines, continuity of care, convenience

vi. Societal - related factors: social support, cultural beliefs, stigma

Some patients start by being adherent to therapy and then they become non-adherent or vice versa, what do you think are the reasons behind such changes in medication-taking behavior?

Strategies to improve adherence

- $\quad$ Based on the problems you told me about, how do you think we can improve?

- What solutions do you think would work for you?

Concluding

Mrs/Mr X, Do you have any additional comments related to medication adherence in diabetes or in general that you would like to share with us?

$\mathrm{Mrs} / \mathrm{Mr} \mathrm{X}$, we have come to the end of the interview.

Thank you very much for your time today and for your honest opinion and fruitful discussions. We greatly appreciate your support.

Figure SI Interviewer's guide (patients with diabetes in Qatar).

Facilitator's guide for interview (health care providers)

The following will be the focus of the discussion during the interview. The thematic questions will be used as prompts and allowing free expression from interviewees Questions asked will be open ended.

Start

Welcome: Interviewer will welcome participants.

General introduction: The interviewer will introduce him/herself.

Objective: State the objective of the study, ensure privacy and freedom of discussion.

Example:

"Thank you for your interest in sharing your experience. My name is __, a research investigator at Qatar University. The main aim of this interview is to identify barriers to medication adherence in patients with diabetes from your perspective as a health care provider and to explore potential solutions for enhancing medication adherence in this patients population. We are very interested to hear your opinions as health care providers and learn from your experiences..."

\section{Ground rules}

8. We would like you to do the talking. Please talk freely; there is no right or wrong answers.

9. Try to reflect on your experiences with patients with diabetes in Qatar.

10. Whatever is mentioned within the room, will stay within the room and will not be linked back to you.

11. We will tape record the discussion to capture everything you have to say, but we will not identify anyone by name in our report, you will remain anonymous. Tape records will be deleted once transcribed.

12. You have the freedom to refuse to answer any question or stop the interview at anytime.

13. We would appreciate if you could please turn off your mobiles to avoid distractions during the session.

14. The duration of this interview is about $45-60$ minutes.

Participant introduction

Ask interviewee to introduce themselves, their work, and how long they have been in Doha for

Example: Can you please introduce yourself? How long have you been practicing in Qatar?

General introductory questions

1. Can you tell me what the term "medication adherence" means to you?

2. How would you label your patients as nonadherent?

3. In your opinion is medication nonadherence a big problem among diabetic patients in Qatar?

4. Generally speaking, what percentage the patients you encounter in your practice would you say are adherent to their medications?

5. What are the questions generally asked by the patients about their mediations? And how do you respond?

Barriers to medication adherence

1. What do you think are the barriers to medication adherence in patients with diabetes that you see in your current practice in Qatar?

2. Why do you think these are barriers to medication adherence?

a Probing: How do you think (factor) affects medication adherence?

b Probing: Can you give example from your practice where you noticed barriers to medication adherence?

- Patient - related factors:

$>$ Demographics (gender, age, education, marital status, ethnicities, financial status)

Figure S2 (Continued) 


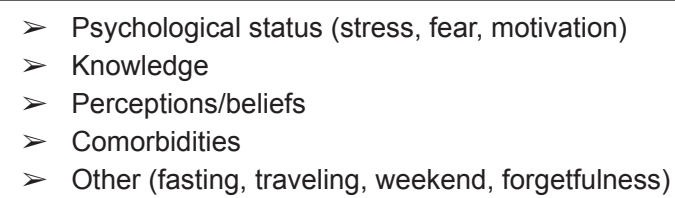

- Medication - related factors: frequency, duration of therapy, polypharmacy, timing, side effects, complexity of treatment, etc

- Disease - related factors: disease duration, complexity, low HbA1c, complications

- Provider - related factors: support, inclusion in decision making, relationship, language, assumptions

- Healthcare system - related factors: cost, lack of guidelines, continuity of care, convenience

- Societal - related factors: social support, cultural beliefs, stigma

3. Some patients start by being adherent to therapy and then they become nonadherent or vice versa, what do you think are the reasons behind such changes in medication-taking behavior?

Strategies to improve adherence

4. How do you deal with nonadherence in your clinical practice?

5. From your experience what has worked/not worked?

6. Are there any strategies used to address medication adherence in patients with diabetes in your practice in Qatar? What are these strategies?

7. How effective do you think these strategies are?

8. What changes do you propose from your perspective that should be applied to improve these already existing strategies (if any)?

9. What other solutions do you propose for improving medication adherence in patients with diabetes in Qatar?

Concluding

1. Do you have any additional comments related to medication adherence in diabetes or in general that you would like to share?

2. Thank you very much for your time today and for your honest opinion and fruitful discussions. We greatly appreciate your support.

Figure S2 Facilitator's guide for interview (health care providers).

Patient Preference and Adherence

\section{Dovepress}

\section{Publish your work in this journal}

Patient Preference and Adherence is an international, peer-reviewed, open access journal that focuses on the growing importance of patient preference and adherence throughout the therapeutic continuum. Patient satisfaction, acceptability, quality of life, compliance, persistence and their role in developing new therapeutic modalities and compounds to optimize clinical outcomes for existing disease states are major areas of interest for the journal. This journal has been accepted for indexing on PubMed Central. The manuscript management system is completely online and includes a very quick and fair peer-review system, which is all easy to use. Visit http://www. dovepress.com/testimonials.php to read real quotes from published authors.

Submit your manuscript here: http://www.dovepress.com/patient-preference-and-adherence-journal 